Covered in: Web of Sciences (WOS); EBSCO; ERIH+; Google Scholar; Index Copernicus; Ideas RePeC; Econpapers; Socionet; CEEOL; Ulrich ProQuest; Cabell, Journalseek; Scipio; Philpapers; SHERPA/RoMEO repositories; KVK; WorldCat; CrossRef; CrossCheck

2018, Volume 10, Issue 3, pages: 91-102 | doi: https://doi.org/10.18662/rrem/65

\section{Metacognition - A Premise for a Qualitative Academic Learning}

Ioana STĂNCESCU1, Luminița Mihaela DRĂGHICESCU², Ana-Maria Aurelia PETRESCU ${ }^{3}$

${ }^{1}$ Lecturer Ph.D., Valahia University, Târgovişte, România, ioanamihai22@yahoo.com; stancescuioana@yahoo.com

${ }^{2}$ Associate Professor Ph.D, Valahia University, Târgovişte, România, lumidraghicescu@yahoo.com

${ }^{3}$ Associate Professor Ph.D., Valahia University, Târgovişte, România, anapetrescu2007@yahoo.com

\begin{abstract}
If we want that our students to practice a qualitative learning, there is a need for a change of optic in the educational process. This change involves shifting the emphasis placed on the activity of the teacher, to the activity of students, who must assume the responsibility of their own learning. In order to make such a change, a fundamental premise is represented by the development of metacognition and related competencies of the students. The metacognition is the knowledge we have about our own cognitive processes, but also its regulation and optimization. Forming and developing of such superior students' capacity can achieve significant benefits in relation to the learning they practice: identifying strengths and vulnerabilities of cognitive style and learning style, assuming learning tasks, optimal selection of the learning strategies, according to proposed / self-proposed goals, adjusting their own learning, correct self-evaluation etc. The present study aims to search the students' opinions related to the qualitative academic learning and on the importance of the development of metacognition within it, identifying and practicing also appropriate strategies in which students can develop their metacognitive competences, as a premise of a qualitive academic learning. The target group of the research is represented by the students enrolled in the Psycho-pedagogical Training Program, the research method being a questionnaire-based survey, supplemented by a focus group.
\end{abstract}

Keywords: academic learning; qualitative learning; metacognition; students' metacognitive competences; strategies for metacognition development.

How to cite: Stancescu, I., Draghicescu, L.M., \& Petrescu, A.-M.A (2018). Metacognition - A Premise for a Qualitative Academic Learning. Revista Romaneasca pentru Educatie Multidimensionala, 10(3), 91-102. https://doi.org/10.18662/rrem/65 


\section{Introduction}

There are many concerns expressed by teachers involved in the university education level, beyond the reflection on their own teaching style, their teaching behavior, their own professional competences, academic learning, quality learning. All those represent a constantly subject for reflection, analysis, aiming to optimize the students' performance and to maximize their potential. Taking into account those concerns, it is necessary to be interested not only by the content proposed for assimilation, of its relevance and usefulness, its organization, structuring and systematisation etc., but also of how our students relate to this content: how do they actually learn? what strategies they use in learning?, what learning style have they developed?, how effective is it?, what support they need to make their learning process more efficient?, how do we stimulate their motivation for learning?

The answers to all those interrogations can be found in the analysis of some of the most widely used concepts in the last decades: academic learning, quality learning, metacognition.

Referring to the synthesis performed by I. Neacşu regarding the significance of an independent academic learning, we note the following relevant considerations:

- "a superior ability to understand, interpret and reinterpret reality perceived and processed in ways that vary with the personality of the learner; a complex mental, affective or motorized exercise, of deep reflection, in alternatives and with multiplier accentuating the universe of the studied knowledge;

- a process of translation of new knowledge, experiences and abilities in cognitive behaviors (facts, concepts, theories, problem solving etc.), emotional (attitudes, values, beliefs, convictions), psychomotors (skills, algorithms, models of skills), socio-moral-characterial and spiritual (...)" (Neacşu, 2006, pp. 15-16).

A quality academic learning can only be a process based on intrinsic motivation, autonomy, self-control, self-regulation and self-direction. In various specialized studies, the concept of self-regulated learning is frequently used. Moreover, given the peculiarities of the educational level at which the academic learning takes place - tertiary education and the peculiarities of those who put it into practice -, we can say that academic learning is, in essence, a self-regulated learning process.

"Although definitions of self-regulated learning involving specific processes often differ on the basis of the researchers' theoretical 
orientations, a common conceptualization of the students has emerged as metacognitively, motivationally, and behaviorally active participants in their own learning" (Zimmerman, 1990, p. 4).

From another point of view, "self-regulated learning consists of three main components: cognition, metacognition, and motivation. The cognition includes skills necessary to encode, memorise, and recall information. The metacognition includes skills that enable learners to understand and monitor their cognitive processes. The motivation includes beliefs and attitudes that affect the use and development of cognitive and metacognitive skills" (Schraw, Crippen, \& Hartley, 2006, p. 112).

By analyzing the relations between self-regulation learning and metacognition, Pintrich, Wolters, and Baxter (2000, p. 45) argue that "selfregulated learning is the more global and inclusive construct, and subsumes metacognition and metacognitive knowledge". In their opinion, "planning, strategy selection, resource allocation, and volitional control comprise on four important aspects of self-regulation and control. In combination with metacognitive judgments and monitoring, they make up the "on-line" process-oriented aspects of metacognition and self-regulated learning" (Pintrich, Wolters, \& Baxter, 2000, p. 53).

The careful reading of the meanings of self-regulated learning leads us to another key concept of this study: metacognition. Practically, metacognition is an intrinsic dimension of this process. Incompletely explored until now, metacognition continues to represent, especially for psychologists and theoreticians of education, a tender field of research, the more so as its educational applications are in an obvious expansion.

Trying to demonstrate the decisive role of metacognition in learning, four decades ago, in one of his studies, Flavell noted (1979, p. 906): investigators have recently concluded that metacognition plays an important role in oral communication of information, oral persuasion, oral comprehension, reading comprehension, writing, language acquisition, attention, memory, problem solving, social cognition, and, various types of self-control and self-instruction; there are also clear indications that ideas about metacognition are beginning to make contact with similar ideas in the areas of social learning theory, cognitive behavior modification, personality development, and education.

In Fisher's optics (1998, p. 1), metacognition refers to "that uniquely human capacity of people to be self-reflexive, not just to think and know, but to think about their own thinking and knowing".

"By definition, metacognition is a higher-order, executive process that monitors and coordinates other cognitive processes engaged during 
learning, such as recall, rehearsal, or problem solving to name a few" (Tobias \& Everson, 2009, p. 108).

If we want our students to pursue a high quality academic learning, it is necessary that among the objectives of each study subject, we also include objectives that explicitly aim to the development of metacognitive processes through specific strategies. In this sense, being concerned about the development of metacognitive competences from the early years of the children, Fischer (1998, p. 9) distinguishes between three categories of didactic strategies: didactic, directed discovery and teaching for metacognition (meta-teaching), highlighting that "meta-teaching aims to mediate metacognition to help the child make explicit their thinking and learning for the purpose of self-appraisal and self-management.

In the literature, there are many recommendations for teachers who understand how important it is to help their students to develop their metacognitive competences. Of course, such an approach involves changing in the teaching style, teaching habits, own habits/automatisms, but no effort should be considered too great, as long as the results of the latest research show unequivocally that "students with good metacognition demonstrate good academic performance compared to students with poor metacognition. Students with poor metacognition may benefit from metacognitive training to improve their metacognition and academic performance (Coutinho, 2007, p. 40).

\section{Problem statement}

Metacognition facilitates high-quality academic learning, determine students to constantly reflect on the strategies used in the process by evaluating their effectiveness, by reporting the learning objectives with the results actually achieved, and making decisions to optimize them or restructure their own style learning if it proves to be ineffective.

Schraw and Dennison (1994, pp. 171-174) describe the components and subcomponents of metacognition: knowledge about cognition and regulation of cognition. Knowledge about cognition consists of three subcomponents: declarative knowledge (the factual knowledge the learner needs before being able to process or use critical thinking related to the topic; knowing about, what, or that; knowledge of one's skills, intellectual resources, and abilities as a learner); procedural knowledge (the application of knowledge for the purposes of completing a procedure or process; knowledge about how to implement learning procedures); conditional knowledge (the determination under what circumstances specific processes or skills should transfer; knowledge 
about when and why to use learning procedures; application of declarative and procedural knowledge with certain conditions presented).

Regulation of cognition consists of five components: planning (planning, goal setting and allocating resources prior to learning); information management strategies (skills and strategies used to process information more efficiently: organizing, elaborating, summarizing, selective focusing); comprehension monitoring (assessment of one's learning or strategy use); debugging strategies (strategies to correct comprehension and performance errors); evaluation (analysis of performance and strategy effectiveness after a learning episode).

Flavell and Brown (Sălăvăstru, 2009; Frumos, 2008) discuss about functional structure of metacognition.

Sălăvăstru (2009, p. 187) describes the two metacognitive components: metacognitive knowledge and metacognitive skills.

Metacognitive knowledge includes person-related knowledge, learning task knowledge and strategy knowledge.

The second component of metacognition is represented by metacognitive skills. Flavell (as cited in Frumos, 2008, p. 82) clasifies the metacognitive skills in three classes: anticipation operations: planning (provision of steps, option for certain strategies according to purpose) and anticipation of results; evaluation and regularization operations, defined by monitoring: supervising ongoing work, distance to goal, identifying and correcting potential errors; terminal evaluation of the result obtained by reference to the purpose.

So, metacognition is a complex and difficult process. It is the knowledge we make in relation to our own cognitive processes, but also their adjustment and optimization.

Forming and practicing such a superior student capacity, students can achieve significant benefits in relation to the learning they practice:

- establishing their own learning objectives;

- knowledge of the conditions that foster their own learning;

- rigorous programming of learning time;

- continuous assessment of their own knowledge, skills and abilities;

- achieving the transfer of knowledge;

- identifying strengths and vulnerabilities of the learning style, assuming learning tasks;

- optimal selection of learning strategies, with reference to proposed / self-propelled objectives;

- correct self-evaluation;

- controlling, regulating your own learning, etc. 


\section{Research Questions/Aims of the research}

Our study aims:

- to research student's opinions on quality academic learning and on the importance of developing metacognition within it;

- to identify and to practice appropriate strategies by which students can develop their metacognitive competences as a prerequisite of quality academic learning.

\section{Research Methods}

The research method used in our study was the survey based on a questionnaire. The subjects of the research were 100 students attending the Initial Psycho-pedagogical Training Program.

The questionnaire consists of twenty-four items (with closed answers and open answers), items that directly addressed to some aspects of student learning and metacognition involved in learning:

- metacognitive knowledge (analysis of the own learning process, knowledge of the conditions which facilitates learning, setting essential and important information in learning, knowledge of strengths and weaknesses of learning style);

- metacognitive regulation (setting learning objectives, planning the learning process, using intellectual work tools, organizing learning material, overcoming learning difficulties, completing learning tasks, taking measures to optimize learning).

The processing of the obtained results was predominantly quantitative, in correlation with the qualitative analysis, based on information obtained from discussions with the students involved.

In the present demarche, we have chosen to exemplify some of the results obtain to relevant items existed in the questionnaire.

\section{Findings}

The first item subsumed to metacognitive knowledge refers to students' analysis of their own learning process. $75 \%$ from students answered that they do an analysis of their own learning process, which lead us to the conclusion that they are interested to achieve a good knowledge of their own learning. Just a small percent of the students answered that they do not perform an analysis of the learning process. 

Ioana STĂNCESCU, et. al.

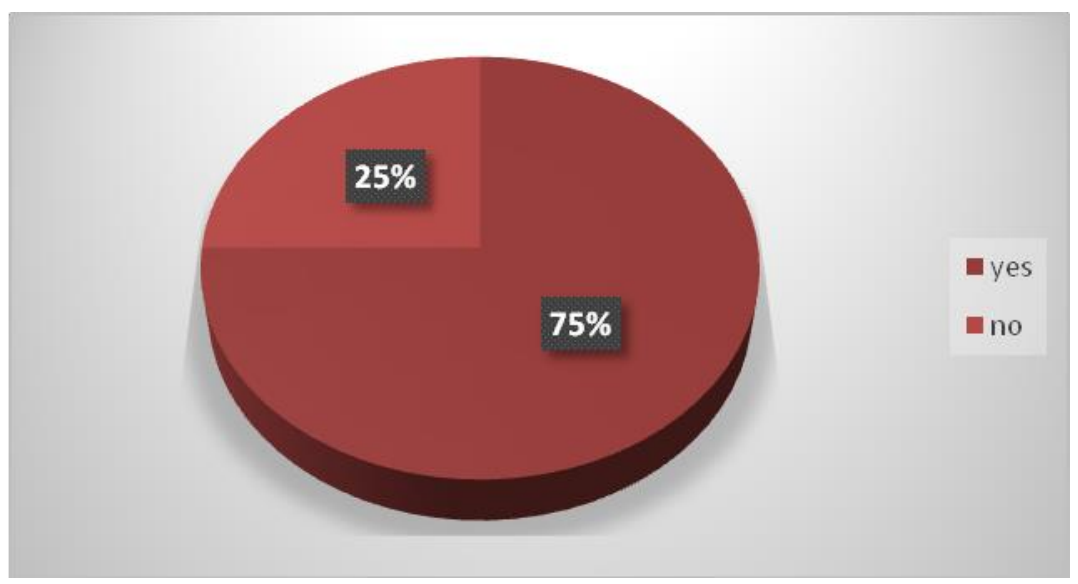

Fig. 1. Students' analysis of their own learning process (Source: author's own conception)

At this item, we asked students to motivate their answers. The students who answered "yes" have presented the following arguments: getting better results (passing exams, higher grades), developing an effective learning style, improving learning, discovering effective learning methods and removing inefficient ones, knowing the level at which they are located. The students who answered "no" motivated their answers: they considered they have a good knowledge of their learning style, so there is no need for such an analysis, allocation of insufficient learning time, lack of motivation to carry out such an analysis, such an analysis is not necessary and appropriate.

Next item of the questionnaire refers to the knowledge of the conditions which facilitates learning.

In the table below, we present the learning conditions mentioned by the students, grouped into four categories: psychological conditions, biological conditions, environmental conditions and conditions related to the material to be studied.

Table 1. The conditions which facilitates learning (Source: author's own conception)

\begin{tabular}{ll}
\hline The conditions which facilitates learning & Percentage \\
\hline $\begin{array}{l}\text { Psychological conditions (concentration, positive emotional } \\
\text { state, optimal motivation, lack of stress, will, self-confidence }\end{array}$ & $35 \%$ \\
and confidence in the success of the learning activity) & \\
\hline Biological conditions (good health, comfort, rest) & $15 \%$ \\
\hline
\end{tabular}


Environmental conditions (broad space, ventilation, brightness, 25\%

cleanliness / order, quietness, adequate temperature)

Characteristics of the material to be studied (structuring, good 25\% organization of the material, material logic, its attractiveness, utility).

Analyzing the data in the table, we can see that the conditions that facilitate the learning, most often mentioned by the students $(35 \%)$ are the psychological ones.

The third item analyzed in our study is represented by the knowledge of strengths and weaknesses of the learning style.

Table 2. Knowledge of strengths and weaknesses of learning style (Source: author's own conception)

\begin{tabular}{|c|c|}
\hline Strengths of students' learning style & $\begin{array}{c}\text { Weaknesses of students' learning } \\
\text { style }\end{array}$ \\
\hline $\begin{array}{l}\text { - } \quad \text { logical learning; } \\
\text { instematization of } \\
\text { - } \quad \text { very good visual memory; } \\
\text { - } \quad \text { organization of the material; } \\
\text { - } \quad \text { use of intellectual work } \\
\text { techniques (highlighting on the } \\
\text { main ideas, drawing up } \\
\text { schemes, annotations, } \\
\text { emphasis on the text); } \\
\text { - } \text { concentration of attention; } \\
\text { - } \text { patience; } \\
\text { correlating new information } \\
\text { - } \text { with existed ones; } \\
\text { - } \text { ponscientiousness; } \\
\text { - } \text { ability to mobilize in stressful } \\
\text { - } \text { situations; }\end{array}$ & $\begin{array}{l}\text { - } \text { inadequate study time; } \\
\text { - lack of focus; } \\
\text { - non-systematization of } \\
\text { information; } \\
\text { - learning "word-for-word" on } \\
\text { some subjects; } \\
\text { - the impossibility of maintaining } \\
\text { motivation throughout the activity; } \\
\text { - insufficient concentration of } \\
\text { attention; } \\
\text { - lecture study (more in session, } \\
\text { less during the year); } \\
\text { - } \quad \text { sometimes disintegrated; } \\
\text { - distraction from learning and } \\
\text { performing collateral activities; } \\
\text { - } \quad \text { superficiality in learning. }\end{array}$ \\
\hline
\end{tabular}

Analyzing carefully the data obtained from this item, we can conclude that the investigated students are aware of the strengths and weaknesses of their learning style. This is very important, because in order to be able to achieve effective, independent and sustainable learning, the first 
step to be taken is to know the strengths (to maintain them) and the weaknesses (in order to improve them) of this process.

Regarding the metacognitive regulation, we present below (Fig. 2) the results obtained by the students to the items of the questionnaire focused on the metacognitive strategies used in the learning process: setting clear goals in learning, making a study program, compliance with the established program, focus on understanding new information, stop learning and return to new and unclear information, timely completing the learning task.

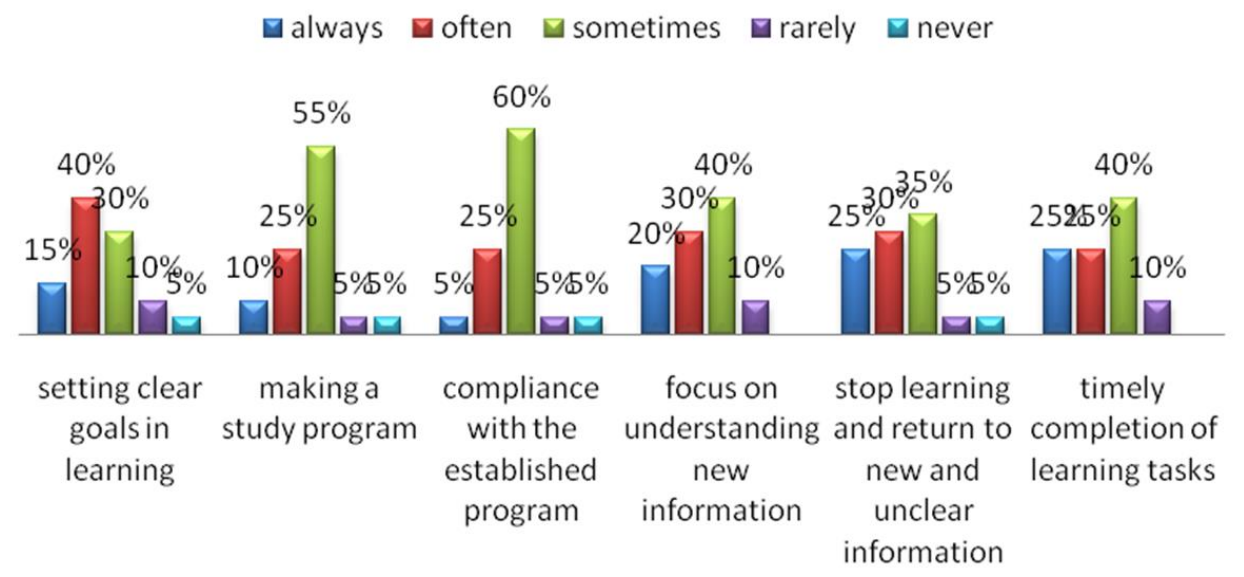

Fig. 2. Metacognitive strategies (Source: author's own conception)

The analysis of the students' answers to the metacognitive strategies items and the obtained percentages lead us to the conclusion that students do not always use appropriate metacognitive strategies either because they are not aware of their role or because they are not well supported, learning how to use these strategies.

Although planning is an important metacognitive strategy from the beginning of the learning activity and on which the success of this activity depends, only $15 \%$ of students say they always set learning goals, and $40 \%$ say they often set goals.

Establishing a rigorous study program and then compliance with it are important metacognitive strategies designed to rationalize learning. Only $10 \%$ of students are always doing a study program and only $25 \%$ often do such a program. Only $5 \%$ of those who make a program always respect it.

At the focus on understanding new information strategy, the percentages are better, meaning that $50 \%$ of students say they practice this strategy (20\% always and $30 \%$ often). This is a very good aspect, because a 
profound learning involves the understanding of the material that students must learn.

Another strategy aimed at understanding the learned information, by stopping learning and then returning to new and unclear information. 25\% of students say they always do this and $30 \%$ of the students say they do this often.

Also, $50 \%$ of students declare that they timely complete the learning tasks (25\% always and $25 \%$ often).

\section{Discussions}

The data analysis leads us to the conclusion that metacognitive aspects are considered important by the surveyed students, but at the same time, represent insufficiently developed and practiced aspects of learning.

The results obtained by the students to the items subsumed to the metacognitive knowledge domain are better compared to those obtained from to the metacognitive regulation related items.

In order to achieve a quality learning, it is necessary to develop both components of metacognition, metacognitive knowledge and metacognitive regulation.

We suggest below some of the possible ways of student' metacognition development:

- creating / completing reflection sheets, metacognitive journals;

- formulating objectives for the exercises proposed in the learning activity;

- realizing a study program and its compliance;

- using the intellectual work techniques and tools;

- planning the steps to be taken in the learning process;

- organizing an optimal learning environment;

- selecting appropriate learning strategies;

- ensuring a permanent feed-back in learning;

- developing students' self-evaluation capacity;

- exercising reflective capacity;

- using interactive strategies (Stăncescu, 2017).

\section{Conclusions}

Starting from the results of our study and from their analysis and interpretation, we believe that for the proper development and training of the metacognitive competences of students, the concerted efforts of the teachers and the students are needed. 
In this demarche, teachers should start from the good knowledge of the students they work with and their own teaching style, and on the basis of this knowledge, they have to organize an adequate, stimulating, motivating educational environment that encourages students to actively be involved in the whole learning process. Then, teachers need to assume the role of guidance, assistance of the student's learning process.

The use of interactive, participative and metacognitive didactic strategies can lead to the development of metacognition of the students over time. Teachers should become reflective practitioners themselves, constantly preoccupied with what is happening in the classroom and improving their own work.

It is not possible to achieve notable metacognitive outcomes if students do not effectively engage in theoretical and applied activities, if they do not maximize the spirit of initiative, independence and creative potential, the capacities to investigate and regulate their own cognitive, affective, motivational processes.

Only developing metacognitive competences, students can achieve a quality, conscious, autonomous, systematic, profound learning.

\section{Acknowledgment}

The contribution of the authors to this paper is equal.

\section{References}

Coutinho, S. A. (2007). The relationship between goals, metacognition, and academic success. Educate Journal, 7(1), 39-47. Retrieved from http://www.educatejournal.org/index.php/educate/article/view/116/134

Fisher, R. (1998). Thinking about thinking: Developing metacognition in children. Early Child Development and Care, 141(1), 1-15. doi:10.1080/0300443981410101

Flavell, J. H. (1979). Metacognition and cognitive monitoring. A new area of cognitive-developmental inquiry. American Psychologist, 34(10), 906-911. doi:10.1037//0003-066x.34.10.906

Frumos, F. (2008). Didactica. Fundamente şi dequvoltări cognitiviste. Iaşi, Romania: Editura Polirom.

Neacşu, I. (2006). Invățarea academică independentă. Ghid metodologic. Bucharest, Romania: Universitatea din Bucureşti, Facultatea de Psihologie şi Ştiințele Educației. Retrieved from http://www.unibuc.ro/uploads_ro/36833/Invatarea_academica_independ enta.pdf 
Pintrich, P. R., Wolters, C. A., \& Baxter, G. P. (2000). Assessing metacognition and self-regulated learning. In G. Schraw, L. Murphy \& J. C. Impara (Eds.), Issues in the measurement of metacognition (pp. 43-98). Nebraska, USA: Buros Institute of Mental Measurements. Retrieved from https://digitalcommons.unl.edu/cgi/viewcontent.cgi?article=1002\&contex $\mathrm{t}=$ burosmetacognition

Sălăvăstru. D. (2009). Psibologia învățării. Iaşi, Romania: Editura Polirom.

Schraw, G., \& Dennison, S. (1994). Assessing metacognitive awareness. Contemporary Educational Psychology, 19(4), 460-475. doi:10.1006/ceps.1994.1033

Schraw, G., Crippen, K. J., \& Hartley, K. (2006). Promoting self-regulation in science education: Metacognition as part of a broader perspective on learning. Research in Science Education, 36(1-2), 111-139. doi:10.1007/s11165005-3917-8

Stăncescu, I. (2017). Metacogniție şi motivație în învăţarea academică. Repere psihodidactice. Bucharest, Romania: Editura Universitară.

Tobias, S., \& Everson, H. T. (2009). The importance of knowing what you know. A knowledge monitoring framework. for studying metacognition in education. In D. J. Hacker, J. Dunlosky \& A. C. Graesser (Eds.), Handbook of metacognition in education (pp. 107-127). New York, USA: Taylor and Francis. Retrieved from

https://zodml.org/sites/default/files/\%5BDouglas_J._Hacker,_John_Du nlosky,_Arthur_C._Graes_0.pdf

Zimmerman, B. J. (1990). Self-regulated learning and academic achievement: An overview. Educational Psychologist, 25(1), 3-17. doi:10.1207/s15326985ep2501_2 